\title{
Statistical Downscaling of General Circulation Model Outputs to Catchment Streamflows
}

\author{
D.A. Sachindra $^{a}$, F. Huang ${ }^{a}$, A.F. Barton ${ }^{a, b}$, and B.J.C. Perera ${ }^{a}$ \\ ${ }^{a}$ Victoria University, P.O. Box 14428, Melbourne, Victoria 8001 \\ ${ }^{b}$ Grampians Wimmera Mallee Water Corporation, P.O. Box 481, Horsham, Victoria, 3402 \\ Email: sachindra.dhanapalaarachchige@,live.vu.edu.au
}

\begin{abstract}
Since the latter half of the 20th century, many regions of Australia experienced a drop in average rainfall, causing low inflows to reservoirs. Until the recent heavy rainfalls of late 2010 and early 2011, Victoria suffered a severe drought commencing 1997. This resulted in a reduction of annual average inflows to Melbourne's main water supply reservoirs of about 38\%, during the period 1997-2008. The Grampians Wimmera Mallee Water (GWMWater) supply system in north-western Victoria also experienced a drop in annual inflows to its reservoirs of about $75 \%$, from the long term average since 1997. Already being the driest inhabited continent in the world, this drop in inflows to reservoirs was of significant concern to water managers across much of Australia. Such a significant deviation from the long term average highlights the importance of being able to reliably predict streamflows considering the likely future climate change and variability, which will ultimately aid in future planning of the water supply systems.
\end{abstract}

General Circulation Models (GCMs) are the most advanced tools available for the simulation of future climate. However, the coarse spatial resolution of GCMs does not allow for hydroclimatic predictions at the catchment scale. Indeed, they are incapable of producing outputs at the fine spatial resolution needed for most hydrological studies. To address this issue, downscaling methods have been developed, which link coarse resolution GCM outputs to surface hydroclimatic variables at finer resolutions. Downscaling techniques are broadly classified as either dynamic or statistical. The computation cost associated with dynamic downscaling methods is much higher than that of statistical downscaling. Another major drawback of dynamic downscaling models is their high complexity. The aim of the present study was to develop a model capable of statistically downscaling monthly GCM outputs to catchment scale monthly streamflows, accounting for the climate change. The current study investigated only the calibration and validation of the abovementioned statistical downscaling model. This was demonstrated through a case study applied to the GWMWater supply system in north-western Victoria, Australia. It is a large scale complex multi-reservoir system that is operated to meet a range of economic, social, and environmental interests.

Support Vector Machine (SVM), a statistical downscaling technique, was used in the current streamflow downscaling exercise. The selection of SVM for downscaling was based on its better capability in capturing complex non-linear relationships between GCM outputs and catchment level variables, than artificial neural networks (ANN) and multi-linear regression (MLR), as observed in the past studies. National Center for Environmental Predictions/National Center for Atmospheric Research (NCEP/NCAR) reanalysis data and observed streamflow data, over the study area, were used for the calibration and verification of the downscaling models. The model calibration (1950-1989) and validation (1990-2010) were performed on each calendar month separately and later results were aggregated to produce the time series of prediction. It was found that, the model was able to produce better predictions over the summer and winter months than in autumn and spring. The model tended to over predict the peaks of streamflows particularly after the 1997 drought in Victoria. It was further observed that the NCEP/NCAR reanalysis variables used in the study did not show a clear change corresponding to the drop in streamflow observed after 1997. The problems associated with the method over the recent severe drought have revealed important information to enable improvements for future model work. Downscaling streamflows from the GCMs skips complex hydrologic modelling, saves time and effort in predicting streamflows. Also, the current work in downscaling streamflows from GCM outputs is believed to be the first in Australia. The present research employed downscaling models based on the 12 calendar months enabling a better capture of streamflow characteristics, unlike the models based on seasons used in the past studies.

Keywords: General circulation models (GCMs), statistical downscaling, support vector machine (SVM), streamflow 


\section{INTRODUCTION}

Climate change caused by the rise in atmospheric Greenhouse Gases (GHG) is a well accepted phenomenon although not without acknowledged uncertainty as to its consequences (Kiem and Verdon-Kidd, 2011). The climate change could affect river flows, water quality and ecology of freshwater bodies. A dependable streamflow forecast will aid in the regulation of runoff and allocation of water for multitude of needs such as domestic water supply, industrial needs plus irrigation and environmental flows. The availability of water in rivers and reservoirs is crucial as this water fulfils many needs of humans as well as flora and fauna. The rising demand for water and the possible decline in future water resources due to the climate change, will pose a significant challenge to water resources authorities (Chiew et al., 2010). The average precipitation over southern half of southeast Australia, during the 1997-2008 period declined by $11 \%$ from the long term average, meanwhile the corresponding runoff drop for the region was $35 \%$ (Chiew et al., 2010). The Australian State of Victoria experienced a severe drought commencing in 1997 and ending only from the recent heavy rainfalls of late 2010 and early 2011. During 1997-2008, the Melbourne water supply system and the Grampians Wimmera Mallee water (GWMWater) supply system in Victoria faced inflow drops of $38 \%$ and $75 \%$ from the long term inflow average to their reservoirs respectively. In these circumstances the prediction of streamflows into future under changing and varying climate is of great importance.

The General Circulation Models (GCMs) are the most advanced tools that are available for the simulation of future climate (Anandhi et al., 2008). These models are capable of predicting climate, hundreds of years into future considering the GHG concentrations in the atmosphere. Ghosh and Mujumdar (2008) regarded GCMs as the most credible tools designed to simulate time series of climate variables, considering the concentrations of GHGs. Although GCMs are among the most advanced tools for predicting the future climate, they are incapable of producing outputs at a finer spatial resolution, needed for most hydrologic studies. The spatial resolution of a present day GCM is coarse, which is in the order of a few hundred kilometers (Tripathi et al., 2006). The coarse resolution does not allow the direct use of GCM predictions at the catchment scale. However, downscaling methods have been developed to link coarse resolution GCM outputs to surface climatic variables at finer resolutions, as a solution to the above issue (Chen et al., 2010). According to Tisseuil et al. (2010), downscaling bridges the large scale atmospheric conditions with local scale climatic data. Downscaling techniques are broadly classified into two categories as dynamic downscaling and statistical downscaling. In dynamic downscaling a Regional Climatic Model (RCM) is nested in a GCM. The RCM is an atmospheric physics based model to which boundary conditions are provided with the output of a GCM. The major drawback of dynamic downscaling is its complexity and high computation cost (Anandhi et al., 2008). The other problem with dynamic downscaling is the propagation of systematic bias from GCM to RCM (Giorgi et al., 2001). Statistical downscaling methods construct statistical relationships between the large scale GCM outputs (predictors) and the catchment scale climate variables (predictands) (Chen et al., 2010). The basic advantage of statistical downscaling is that it is computationally less demanding compared to dynamic downscaling.

According to Wilby and Wigly (2000), statistical downscaling is based on few assumptions. These assumptions are that the predictor-predictand relationships are valid under future climatic conditions, and predictor variables and their changes are well characterised by GCMs. In general, statistical downscaling techniques are classified into three main categories as weather classification, regression models and weather generators. Weather classification methods classify large scale atmospheric variables of GCMs into finite number of states and relate them to basin scale climate variables. Regression methods build up linear or nonlinear functions between predictors and predictands (Chen et al., 2010). Weather generators produce a synthetic series of climate data, while preserving statistical attributes of the observations of climate variables (Wilks and Wilby, 1999).

Statistical downscaling of GCM outputs to catchment scale climatic variables has gained wide application in hydro-climatology. In literature, there are number of studies performed on downscaling GCM outputs to catchment level climatic variables such as precipitation and temperature. Tripathi et al. (2006) used Support Vector Machine (SVM) and Artificial Neural Networks (ANN) for forecasting monthly precipitation. Chen et al. (2010) utilized SVM and Multiple Linear Regression (MLR) to predict daily rainfall. Anandhi et al. (2009) downscaled monthly maximum/minimum temperatures with the SVM technique. Huth (2002) downscaled daily mean temperature using MLR. Generalized Additive Models (GAM) were applied to predict 6 hour mean wind speeds by Salameh et al. (2009). In downscaling literature, only a few studies have been done on downscaling GCM predictors directly to streamflow. Tisseuil et al. (2010) used GAM, Generalized Linear Models (GLM), Aggregated Boosted Trees (ABT) and ANN for predicting daily streamflows. Ghosh and Mujumdar (2008) applied SVM and Relevance Vector Machine (RVM) to predict 
monthly streamflows. Cannon and Whitfield (2002) developed a model using ANN for downscaling GCM outputs to streamflows. Landman et al. (2001) forecasted seasonal streamflows using Canonical Correlation Analysis (CCA) and Perfect Prognosis method.

Tisseuil et al. (2010) state that direct downscaling of GCM predictors to streamflows permits forecasting flows at a large spatial scale under changing climate, since the formulation of a direct relationship between streamflows and GCM outputs allows the generalisation and extrapolation of streamflow over a large area. One shortcoming of direct downscaling of GCM predictors to streamflows is that it simplifies the naturally complicated hydrologic cycle to a great extent, neglecting the influences of land use, soil cover, and groundwater storage on streamflow. The other major limitation of this technique is that it could only be used to predict unregulated streamflows in a catchment. This is because the statistical relationships derived between predictors and streamflows are independent of human regulations such as diversions and storages.

The objective of the current study was to calibrate and validate a statistical downscaling model based on Least Square Support Vector Machine (LS-SVM) regression to downscale monthly GCM outputs directly to monthly streamflows. The objective was demonstrated through a case study applied to a streamflow station at GWMWater supply system in north-western Victoria. This paper discusses only the calibration and validation of the abovementioned streamflow forecasting model. Streamflow forecasting into future with the calibrated and validated model will be detailed in a future paper.

\section{STUDY AREA AND DATA}

The GWMWater system is a large multi-reservoir water supply system located in north-western Victoria, which was used as the case study for the present research. Prediction of streamflows in GWMWater's catchment is crucial, as the system provides water for many domestic, industrial and irrigation needs. The current downscaling study limits its scope to a single streamflow site in the study region.

For the calibration and validation of the downscaling model, National Center for Environmental Predictions/National Center for Atmospheric Research (NCEP/NCAR) monthly reanalysis data and monthly observed streamflow data at a streamflow site from 1950-2010 were used. These reanalysis data are the outputs of a GCM, corrected and quality controlled at several stages (Kalnay et al., 1996). Therefore, the reanalysis data are considered to be predictions of an ideal GCM (Cannon and Whitfield, 2002). The NCEP/NCAR reanalysis data were downloaded from the website (http://www.esrl.noaa.gov/psd/) of National Oceanic \& Atmospheric Administration/Earth System Research Laboratory (NOAA/ESRL) Physical Sciences Division. The quality controlled observed monthly streamflow record at the site concerned was obtained from GWMWater.

\section{METHODOLOGY}

The statistical downscaling of GCM outputs to any hydroclimatic variable involves building statistical relationships between GCM predictors and the catchment level hydroclimatic variables. In the present study, the catchment level variable was the monthly streamflow at a station and the predictors were the monthly NCEP/NCAR reanalysis variables. As mentioned in the Introduction, there is a wide variety of downscaling techniques in use. In this exercise, LS-SVM regression (LS-SVM-R) was employed to downscale NCEP/NCAR predictors to streamflows. Since the hydroclimatology at a certain point in a catchment is influenced by the atmosphere above and around it, a substantially large atmospheric domain was defined. Based on literature and hydrology a set of probable predictors corresponding to this atmospheric domain was extracted from the NCEP/NCAR reanalysis variables. The time series of streamflows and the potential predictors for each calendar month were separated into 20 year time slices. For each of these 20 year time slices, the Pearson correlation coefficients were calculated for each calendar month to identify the predictors which are mostly correlated with the streamflows. The best consistently correlated predictors over the three time slices were selected as potential predictors for the calibration and validation of the model. The consistency of the Pearson correlation between a predictor and streamflow was an important attribute since a good predictor of streamflow should show a consistent relationship over time. These potential predictors for the calibration period were standardised for each calendar month, based on their means and standard deviations for the calibration period. The standardisation of the potential predictors in the validation period was performed with the means and standard deviations corresponding to the calibration period of the data set. The model calibration and validation were performed for each calendar month by introducing the above standardised potential predictors to the LS-SVM-R model. This was done by initially inputting the three best correlated potential variables to the model for a certain month and adding the next best variables one by one, until the model performance is maximised for validation. The model calibration was performed with leave- 
one-out cross-validation and the validation was done as an independent simulation fixing the optimum model parameters yielded in calibration. The model performances in calibration and validation in each month were monitored with Nash-Sutcliffe efficiency (N-S). The generic methodology described here was applied to a streamflow site (inflow to the Bellfield reservoir) within the GWMWater supply system as a demonstration.

\subsection{Overview of LS-SVM-R}

SVM is a machine learning technique which has classification and function approximation capabilities. The concept of SVM classification (SVM-C) was first developed in 1960s. SVM regression (SVM-R) for function approximation was introduced in 1996 (Drucker et al., 1997). A detailed description on SVM theory is found in Vapnik (1999). SVM has a wide applicability in real world phenomena. Lin et al. (2006) predicted long-term river discharges with the SVM-R technique. Chen et al. (2010) and Ghosh and Mujumdar (2008) used SVM-R for downscaling GCM outputs to rainfall and streamflows respectively.

LS-SVM is a simplified variant of original SVM which still preserves the qualities and advantages of the original SVM version (Zhou et al., 2011). The current study employed the LS-SVM regression (LS-SVM-R) to develop the downscaling model, due to its low computation cost and good generalisation performances (Suykens and Vandewalle. 1999). In SVM, a non-linear mapping function is used to map the non-linear input space to into a linear higher dimensional feature space (Tripathi et al., 2006). This process of mapping is simplified by a function called the kernel. There are several types of kernels available in the LS-SVM-R model, such as the linear, polynomial and radial basis function (RBF). In the LS-SVM-R model there are two types of tuning parameters in use, one is the regularisation parameter and the others are kernel parameters. The number of kernel parameters varies from kernel to kernel, but the regularisation parameter remains the same. When the LS-SVM-R model is used with the RBF kernel, $\gamma$ and $\sigma^{2}$ becomes the model tuning parameters, where $\gamma$ is the regularisation parameter and $\sigma$ is the width of the RBF kernel.

According to Zhou et al. (2011) due to its simplified algorithm, LS-SVM requires much less effort in model training when compared with that of the original SVM. Due to these advantages, many researchers have applied LS-SVM in their research work. Zhou et al. (2011), Anandhi et al. (2009) and Tripathi et al. (2006) employed LS-SVM-R for downscaling GCM outputs to catchment scale hydroclimatic variables.

\section{APPLICATION}

\subsection{Selection of atmospheric domain for downscaling}

The climate at a certain point on the ground is governed by a huge atmospheric domain above and around it. The exact dimensions of this influential atmospheric domain are unknown. In past literature, various authors have used different domain sizes for their atmospheric domain. Ghosh and Mujumdar (2008) used a 5 x 5 grid points around the study area for downscaling streamflows, while Tripathi et al. (2006) and Anandhi et al.(2008) used grids with $6 \times 6$ and $3 \times 3$ points for downscaling precipitation respectively. The present study uses a substantially large atmospheric domain of $7 \times 6$ grid points (each $2.5^{0}$ apart), while maintaining symmetry around the study area as shown in Figure 1.

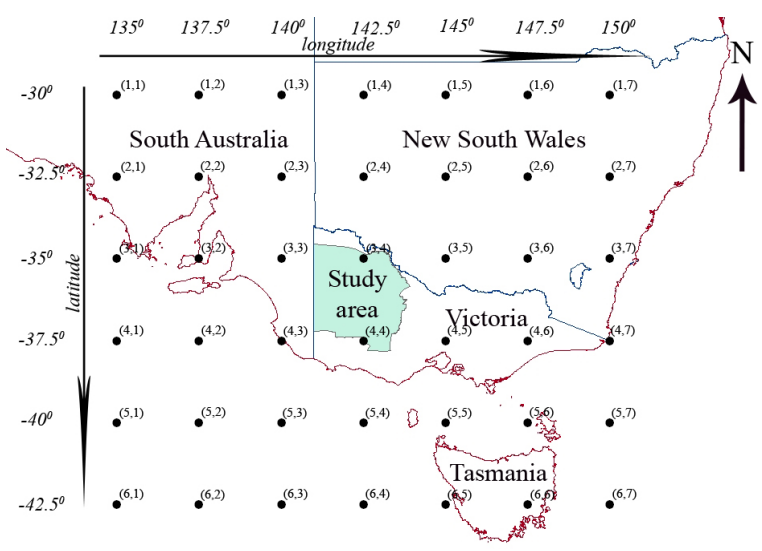

Figure 1. Atmospheric domain around GWMWater supply system used for downscaling

\subsection{Selection of probable and potential predictors for downscaling}

The selection of probable predictor variables is regarded as the beginning of any downscaling activity. A GCM could produce large number of different outputs, but out of those only some of the predictors are more likely to influence the predictand. This subset of all the predictors is called the pool of probable predictors (Anandhi et al., 2008). These probable predictors vary from predictand to predictand. In general, probable predictors for a downscaling study are selected based on past literature. In the present study, for downscaling of GCM predictors to streamflows, probable predictors were selected based on past literature as well as hydrology. 
The 23 probable predictors selected for the downscaling exercise included, geopotential height at $200 \mathrm{hPa}$, $500 \mathrm{hPa}, \quad 700 \mathrm{hPa}, \quad 850 \mathrm{hPa}, \quad 1000 \mathrm{hPa}$ pressure levels, relative humidity at $500 \mathrm{hPa}, 700 \mathrm{hPa}, 850 \mathrm{hPa}, 1000 \mathrm{hPa}$ pressure levels, specific humidity at $2 \mathrm{~m}$ height, $500 \mathrm{hPa}, 850 \mathrm{hPa}, 1000 \mathrm{hPa}$ pressure levels, air temperature at surface, $2 \mathrm{~m}$ height, $500 \mathrm{hPa}, 850 \mathrm{hPa}, 1000 \mathrm{hPa}$ pressure levels, surface skin temperature, surface pressure, mean sea level pressure, volumetric soil moisture content in the $0-10 \mathrm{~cm}$ soil layer and 10-200cm soil layer. Each of these predictors had a spatial dimension of 7 × 6 over the atmospheric domain shown in Figure 1. The volumetric soil moisture contents in the $0-10 \mathrm{~cm}$ and $10-200 \mathrm{~cm}$ soil layers were selected as probable variables purely based on the hydrology and the reset of the probable predictors were selected based on past streamflow downscaling studies by Tisseuil et al. (2010), Ghosh and Mujumdar (2008), Cannon and Whitfield (2002) and Landman et al. (2001).In this study the above 23 probable predictors were considered to be common for all the calendar month of the year, for the streamflow station considered. These probable predictors were selected from the NCEP/NCAR reanalysis data pool. The NCEP/NCAR reanalysis data pool is widely used for the calibration and validation of downscaling models for variety of predictands.

Potential predictor variables are a subset of probable variables which vary form streamflow station to station as well as from season to season. The set of potential predictors is the most influential variable set on streamflows, which is a subset of the probable predictor pool. Predictor-predictand relationships vary seasonally due to changes in atmospheric circulations. Therefore, seasonal models based on wet/dry seasons (Chen et al., 2010) or the four seasons of summer, autumn, winter and spring (Timbal, 2009) have been used in the past. In this study, downscaling models based on calendar months were developed to better capture the seasonal variability of streamflow.

In the current exercise, the Pearson correlation coefficient was used to identify the potential variables for each calendar month. The records of streamflow and NCEP/NCAR probable predictors from 1950 to 2010 were considered under three 20 year time slices 1950-1969, 1970-1989 and 1990-2010. The probable variables which displayed the best, statistically significant (95\% confidence level, $p=0.05$ ) correlation with the streamflow, consistently over the three 20 year time slices were selected as potential variables. From the same probable predictor pool, potential predictors for each calendar month were extracted.

\subsection{LS-SVM-R downscaling model calibration and validation}

The LS-SVM-R model considered in the present study had two tuning parameters $\gamma$ and $\sigma^{2}$ where $\gamma$ is the regularisation parameter and $\sigma$ is the width of the RBF kernel. According to Tripathi et al. (2006) RBF kernel can map non-linear predictor-predictand relationships effectively to a higher dimensional space. The relationship between the streamflows and GCM predictors has a highly complicated non-linear nature. Since Tripathi et al. (2006), Anandhi et al. (2008) and Cheng et al. (2006) have applied RBF kernel successfully in their downscaling exercises, following that, the current study employed the same kernel.

In this study the LS-SVM-R downscaling model was calibrated for the 40 year period 1950-1989 and validated for the 21 year period 1990-2010.Before the calibration and validation of the downscaling model the potential predictors used as inputs to the model were standardised. The standardisation of NCEP/NCAR predictors scales down the data and eliminates the units of the variables. For the model calibration, the NCEP/NCAR potential predictors selected for each month were standardised by the subtracting the mean and dividing by the standard deviation corresponding to the calibration period 1950-1989. Also in validation, the potential predictors were standardised using the same mean and standard deviation corresponding to the calibration period. In model calibration these standardised potential variables were introduced to the LSSVM-R model in such way that, initially the three best correlated variables and then the other best correlated variables one by one. The model calibration was performed using the leave-one-out cross validation and the model parameter optimisation was based on the simplex algorithm. The model validation was done as an independent simulation fixing the optimum values of the tuning parameters, yielded in calibration. The model which displayed the highest performance in validation was considered as the optimum model. By this way the optimum number of inputs to the model was determined. The same calibration and validation process was repeated for each calendar month. The Figure 2 shows the variation of observed monthly flow and LS-SVM$\mathrm{R}$ downscaling model predicted monthly flow for the calibration (1950-1989) and validation (1990-2010) phases. The predictions of the calendar month based models were aggregated to produce a continuous time series of streamflow from 1950-2010. In the model calibration the values of $\gamma$ and $\sigma^{2}$ varied significantly over the 12 months of the calendar ( $\gamma$ range 7.5-998 and $\sigma^{2}$ range 3.8-9901). The model displayed N-S coefficients of 0.73 and 0.47 in calibration and validation respectively. 


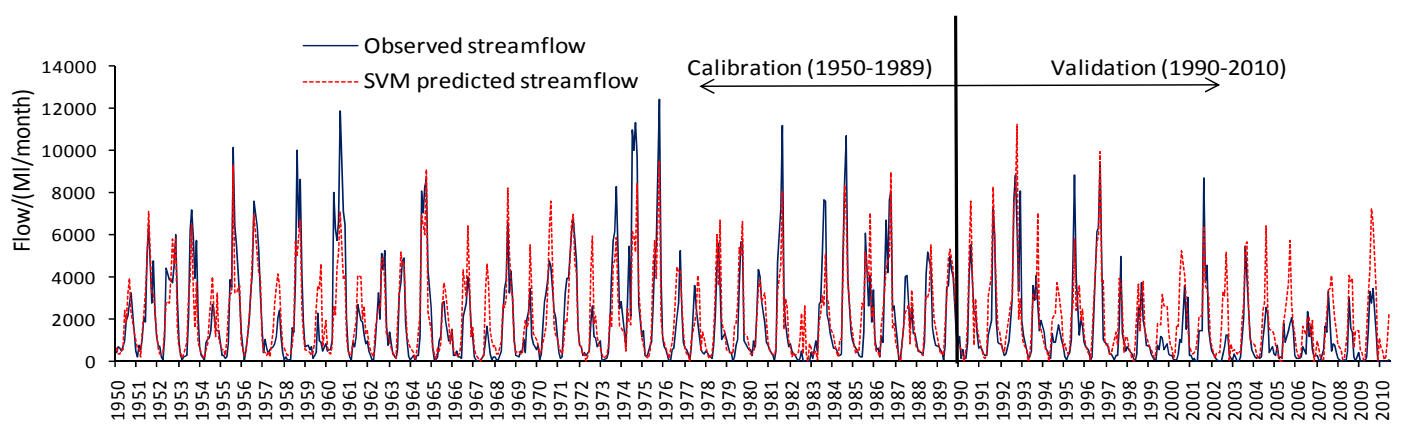

Figure 2. Observed streamflow and SVM predicted streamflow.

Figure 3 shows the scatter plots corresponding to the calibration and validation phase. According to these scatter plots it was clear that in calibration, the model had a tendency of under-predicting peak flows and in validation it had a peak flow over-predicting trend. Further, both in calibration and validation zero flows were largely overpredicted by the model. The overprediction of flow was very evident after 1997, during the validation phase which is depicted in Figure 2.
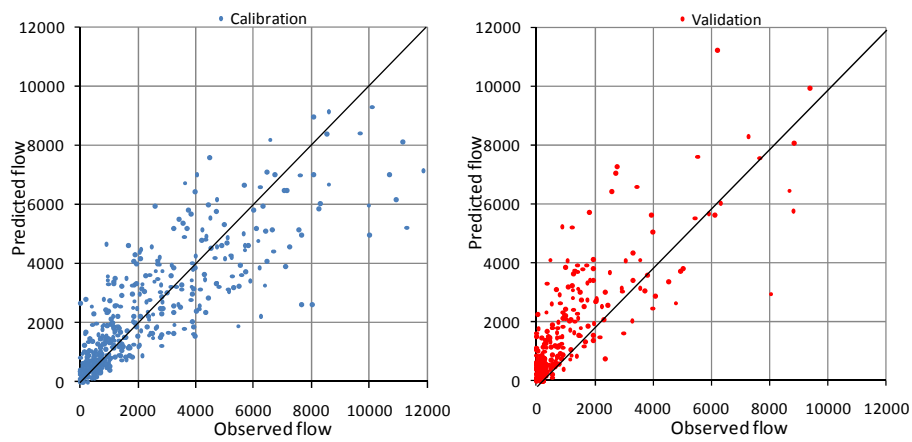

Figure 3. Scatter plots for calibration and validation of the model

Table 1. N-S coefficients in Seasons

\begin{tabular}{|l|c|c|}
\hline Season & Calibration & Validation \\
\hline Summer & 0.55 & 0.39 \\
\hline Autumn & 0.45 & -2.46 \\
\hline Winter & 0.56 & 0.38 \\
\hline Spring & 0.62 & 0.16 \\
\hline
\end{tabular}

As given in table 1, performances of the model had a clear seasonal variation. Among the four seasons summer and winter had the best $\mathrm{N}-\mathrm{S}$ coefficient in the validation periods. Meanwhile autumn had the poorest prediction accuracy which was denoted by an N-S efficiency of -2.46. In the seasons of autumn and spring the model performed far better in calibration than in validation.

\section{DISCUSSION AND CONCLUSIONS}

The use of volumetric soil moisture content in the $0-10 \mathrm{~cm}$ soil layer and $10-200 \mathrm{~cm}$ soil layer for predicting streamflows had not been observed in any of the past studies performed on downscaling GCM outputs to catchment level streamflows. The variations in soil moisture content are highly associated with the atmospheric variability therefore the inclusion of soil moisture in a model could improve the climatic predictions. Further, the soil moisture governs the amount of water retained in soil influencing the rainfall and runoff relationship, and hence streamflows. The limited forecasting ability of the downscaling model in autumn in the current study was very consistent with the findings of Robertson and Wang (2008) where a Bayesian joint probability model was employed to forecast seasonal streamflows. This is mainly because the catchments in Victoria are usually at a dry state during the period leading to autumn, and during autumn, catchments wet up so it absorbs water, but this water makes little or no contribution to streamflow. The over prediction of peak streamflows after 1997 by the model was an evident phenomenon. When the time series plots of the NCEP/NCAR predictors were observed, an obvious change corresponding to this period was not seen. This suggested that the poor performance of the model after 1997 was due to the missing climate change signal in the NCEP/NCAR predictors. The streamflows also displayed poor correlations with the SOI index (El Niño Southern oscillation index) and NINO 3.4 index. Future work will continue the hunt for possible climate change signals. The downscaling model developed in the current study showed reasonable capability in predicting the streamflows in summer and winter although it failed largely in autumn. Downscaling streamflows from the GCMs skips complex hydrologic modeling, saves time and effort in predicting streamflows. In the present investigation NCEP/NCAR reanalysis data were used for the model calibration and validation meanwhile the future streamflow prediction will be done with the HadCAM3 GCM outputs. 


\section{ACKNOWLEDGMENTS}

The authors acknowledge the financial assistance provided by the ARC linkage grant no LP 100100554.

\section{REFERENCES}

Anandhi, A., Srinivas, V.V., Kumar, D.N., and Nanjundiah, R.S. (2009). Role of predictors in downscaling surface temperature to river basin in India for IPCC SRES scenarios using support vector machine. International Journal of Climatology, 29, 583-603.

Anandhi, A., Srinivas, V.V., Nanjundiah, R.S., and Kumar, D.N. (2008). Downscaling precipitation to river basin in India for IPCC SRES scenarios using support vector machine. International Journal of Climatology, 28, 401-420.

Cannon, A.J., and Whitfield, P.H. (2002). Downscaling recent streamflow conditions in British Columbia Canada using ensemble neural network models. Journal of Hydrology, 259, 136-51.

Chen, T.S., Yu, P.S., and Tang, Y.H. (2010). Statistical downscaling of daily precipitation using support vector machines and multivariate analysis. Journal of Hydrology, 385, 13-22.

Chiew, F.H.S., Young, W.J., Cai, W., and Teng, J. (2010). Current drought and future hydroclimate projections in southeast Australia and implications for water resources management. Stochastic Environmental Research and Risk Assessment, 25,602-612

Drucker, H., Burges, C.J.C., Kaufman, L., Smola, A., and Vapnik, V. (1997). Support vector regression machines. Advances in Neural Information Processing Systems, 9, 155-161.

Ghosh, S., and Mujumdar, P.P. (2008). Statistical downscaling of GCM simulations to streamflow using relevance vector machine. Advances in Water Resources, 31, 132-146.

Giorgi, F., Hewitson. B., Christensen, J., Hulme, M., Von Storch, H., Whetton, P., Jones, R., Mearns, L., and Fu, C. (2001). Climate change 2001, The scientific basis, contribution of working group I to the third assessment report of the IPCC, Published online at http://www.grida.no/, Chapter 10, 583-638.

Huth, R. (2002). Statistical downscaling of daily temperature in central Europe. Journal of Climate, 15, 1731-1742.

Kalnay, E., Kanamitsu, M., Kistler, R., Collins, W., Deaven, D., Gandin, L., Iredell, M., Saha, S., White, G., Woollen, J., Zhu, Y., Chelliah, M., Ebisuzaki, W., Higgins, W., Janowiak, J., Mo, K.C., Ropelewski, C., Wang, J., Leetmaa, A., Reynolds, R., Jenne, R., and Joseph, D. (1996). The NCEP/NCAR reanalysis project. Bulletin of the American Meteorological Society, 77, 437-471.

Kiem, A.S.,and Verdon- Kidd, D.C. (2011). Adapting to climate variability and change: limitations of relying on climate model outputs. 33 ${ }^{\text {rd }}$ Hydrology \& Water Resources Symposium, 26 June - 1 July 2011, Brisbane, Australia, 802-809

Landman, W.A., Mason, S.J., Tyson, P.D., and Tennant, W.J. (2001). Statistical downscaling of GCM simulations to streamflow. Journal of Hydrology, 252, 221-236.

Lin, J.Y., Cheng, C.T., and Chau, K.W. (2006). Using support vector machines for long-term discharge prediction. Journal of Hydrological Sciences, 51, 599-612.

Robertson, D. E., and Wang, Q.J. (2008). An investigation into the selection of predictors and skill assessment using the Bayesian joint probability (BJP) modelling approach to seasonal forecasting of streamflows. CSIRO Water for a healthy country flagship report

Salameh, T., Drobinski, P., Vrac, M., and Naveau, P. (2009). Statistical downscaling of near-surface wind over complex terrain in southern France. Journal of Meteorology and Atmospheric physics, 103, 253-265.

Suykens, J.A.K., and Vandewalle, J. (1999). Least squares support vector machine classifiers. Neural Process Lett. 9, 293-300.

Timbal, B., Fernandez, E., and Li, Z. (2009). Generalization of a statistical downscaling model to provide local climate change projections for Australia. Environmental Modeling and Software, 24, 341-358.

Tisseuil, C., Vrac, M., Lek, S., and Wade, A.J. (2010). Statistical downscaling of river flows. Journal of Hydrology, 385, 279-291.

Tripathi, S., Srinivas, V.V., and Nanjundiah, R.S. (2006). Downscaling of precipitation for climate change scenarios: a support vector machine approach. Journal of Hydrology, 330, 621-640.

Vapnik, V. (1999). The Nature of Statistical Learning Theory. Springer-Verlag, New York.

Wilby, R.L., and Wigley, T.M.L. (2000). Precipitation predictors for downscaling: observed and general circulation model relationships. International Journal of Climatology, 20, 641-661.

Wilks, D.S., and Wilby, R.L. (1999). The weather generation game: A review of stochastic weather models. Progress in Physical Geography, 23, 329-357.

Zhou, J., Shi, J., and Li, G. (2011). Fine tuning support vector machines for short-term wind speed forecasting, Energy Conversion and Management, 52, 1990-1998. 